\title{
Experimental Study on the Safety Monitoring System of Rock Mass Acoustic Emission
}

\author{
Zhang Qing \\ School of Civil Engineering \\ Jilin Jianzhu University \\ Chang chun, China \\ zhang_qing_z@126.com
}

\begin{abstract}
A low cost, high performance safety monitoring system of rock mass acoustic emission which is able to complete wireless transmission has been established through adjustment of the present safety monitoring system. The experimental study of rock mass acoustic emission demonstrated that the improved system is suitable for the safety monitoring of rock mass.
\end{abstract}

Keywords—rock mass; acoustic emission; safety monitoring

\section{INTRODUCTION}

Acoustic emission refers to the instantaneous elastic wave generated by the rapid release of energy from the local stress concentration source in the material. The acoustic emission phenomenon will be produced by the micro deformation when the solid materials are in force. Apparatus for detecting, recording, analyzing acoustic emission signals and using acoustic emission signals as an instrument for inferring the acoustic emission source is called an acoustic emission detection system or an acoustic emission monitoring system, which is usually referred to as the acoustic emission system [1].

Acoustic emission system, as a dynamic non-destructive testing method, has been widely used in petrochemical industry, civil engineering, metal processing, material testing, and transportation, aerospace and other fields [2]. Acoustic emission technology has been applied to nondestructive testing for the first time since 1964, and it has been developed rapidly in recent 50 years. Digital acoustic emission instrument has basically replaced the analog acoustic emission instrument[3]. Digital acoustic emission instrument has the advantages of small size, light weight, wide detection range, high accuracy and high integration. In this paper, the designed rock acoustic emission instrument can be used widely, not only can be used in mines, caves, mountain blasting, safety assessment of cave excavation and other process, it can also be used for the prediction and analysis of natural disasters such as geological detection, landslides, debris flow and so on.

Rock mass is a geological body, which has a certain rock composition, a certain structure, and occurs in a certain geological environment after many times, repeatedly, and longterm geological effects [4]. Some complex rock mass constructions has high ground stress, high osmotic pressure, high earthquake intensity such as reservoir dam, reservoir, slope excavation, underground excavation, deep mining, deep coal mining. How to ensure the safety and stability of rock mass engineering construction and operation in the process of large scale excavation, anchoring, seepage control and reservoir, is the vital problem to solve for geotechnical researchers.

The internal defects or potential defects of rock mass are in the process of movement. The rock mass sends out elastic stress wave, which is released by the acoustic emission mode, and can be used to judge the actual state of the rock mass by means of the acoustic signal. However, the sound wave released by rock has its unique characteristics, the frequency is relatively concentrated in the process of rupture[5], and the acoustic wave amplitude is small. Besides, under different temperature, humidity and pressure conditions, different kinds of rock have features as large dispersion, strong randomness and poor repeatability. Thus the acoustic emission instrument for rocks requires characteristics as high accuracy, high resolution and low noise. The acoustic emission signals for rocks are various, and are widely different under different temperature, humidity, pressure conditions. Therefore, Rock mass acoustic emission monitoring system is particularly important for research on rock mass safety. The safety of rock mass can be judged through the reliable security monitoring system and the corresponding emergency treatment can be made according to the actual situation. At the present stage, the safety monitoring system of rock mass is mostly used in laboratory research. The corresponding improvement will be made when the rock acoustic emission monitoring system is applied to the practical engineering, in order to meet the practical requirements of the actual project. The main considerations of the safety monitoring system for rock acoustic emission are as follows:

A. The safety monitoring system of rock mass acoustic emission is connected with the data bus directly. The data can't be pretreated, and the actual state of the rock can't be judged by the acoustic emission data.

$B$. Rock acoustic emission monitoring system can't be used for wireless transmission, real-time is difficult to guarantee. The Rock mass exploitation is huge, and the actual construction position is far from the office, if is unable to obtain the real-time data, the applicability will be difficult to guarantee [6].

C. The safety monitoring system for rock acoustic emission is very expensive, and the operation is much complicated that requires professional technical to operate. It is rather difficult to use for the actual engineers in real project, so 
the actual situation of the construction site cannot be real-time monitored.

Based on the above, the corresponding improvements has been made on the present rock acoustic emission monitoring system, and experiments were made to test the applicability of safety monitoring system in rock mass construction.

\section{DEVELOPMENT OF ACOUSTIC EMISSION SYSTEM}

There are many kinds of acoustic emission signals of rock, which are great different under different temperature, humidity and pressure conditions. When rock mass is subjected to external force, the sound wave intensity of rock is very low when its stress filed is destroyed, which needs special sensor to measure. So in this stage, we can use variable resistors partial pressure sensor instead of analog sensor to save the cost of the corresponding rock mass acoustic emission monitoring system. Use DS18b20 sensor instead of the digital sensors that might be used, collect and transmit the temperature information of the monitoring sites for the upper computer operator to analysis. The sound signal of the system uses the lower computer (PIC16F873a) to collect the sensor data, then transfer them to the host computer after a simple transformation. Data analysis and understanding is done by the host computer.

The current rock mass acoustic emission monitoring system cannot carry out remote data transmission and reflect its real-time nature. The wireless mode communication method between the PIC microcontroller and the host computer was adopted in this design. Based on the distance of transmission, disturbance characteristics, post networking possibilities and other factors into account, the multi-channel micro-power embedded wireless data transmission module was adopted in this design. The module is highly integrated; using half duplex mode, and cyclic interleaving correcting encoding, the sensitivity and anti-interference ability is greatly enhanced. By using the PIC's serial interface program software, data was sent to the microcontroller serial port by using $\mathrm{C}$ language and through the wireless data transmission module. No special consideration is needed for this module. The wireless data transmission module is compatible with the TTL level, which is directly powered by the development board RX, and the TX is on the serial port.

C language was used to operate 10-bit ADC inside the PIC microcontroller and programming, and data acquisition was made for analog output sensors. Data acquisition was made for the digital output sensor by using the universal IO port with precise time delay process. The editing process of the software as shown in Fig. 1, First initialize the IO of the sensor, and then initialize the ADC components inside PIC, carries on the corresponding circulation afterwards, detect the acquisition results of ADC and LCD, finally use wireless module to send data acquisition results. The software flow of the wireless data transmission is shown in Fig. 2. First initialize the wireless data transmission module and enter the main loop, if wireless data was transmitted successfully, and then software program edition was finished. Otherwise, carries on the edition procedure, until it succeeded.

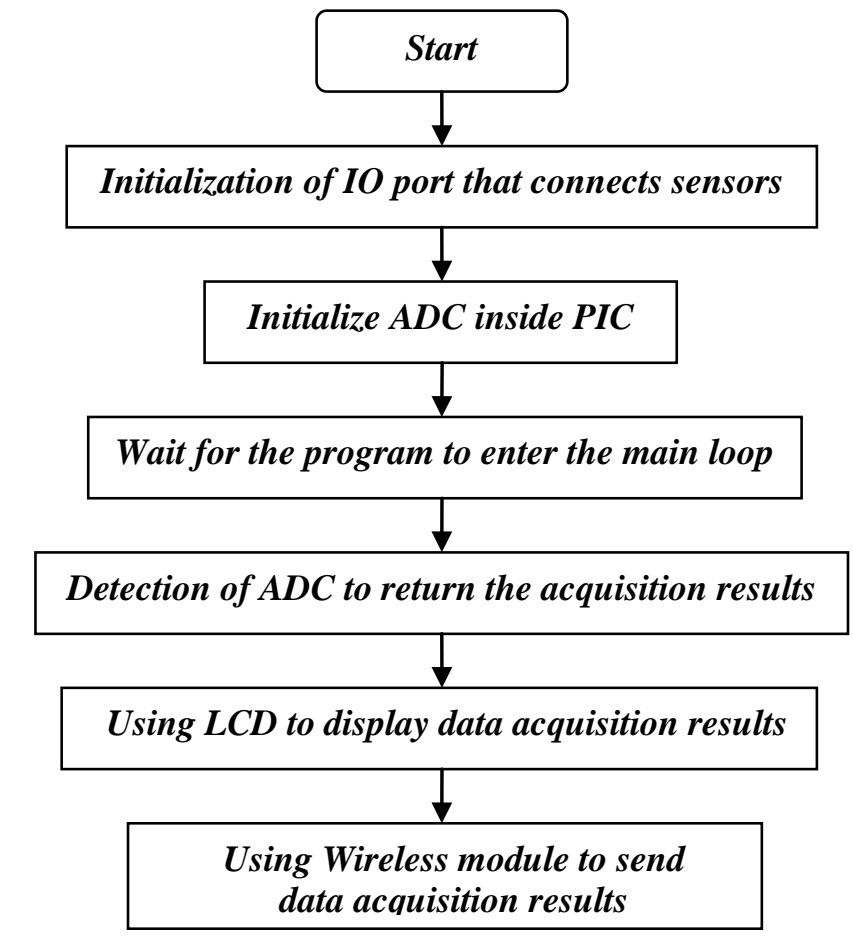

Fig. 1. Software program edit flow chart

Part of the procedure is as follows:

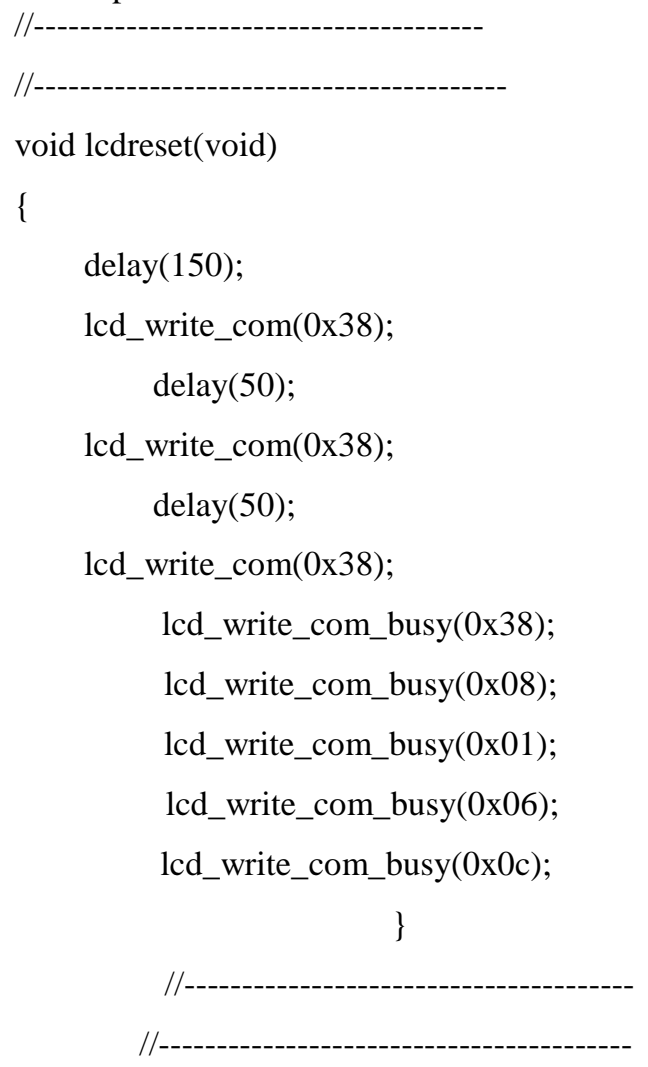

void lcd_write_char(unsigned char x,unsigned char y,unsigned char buf) 


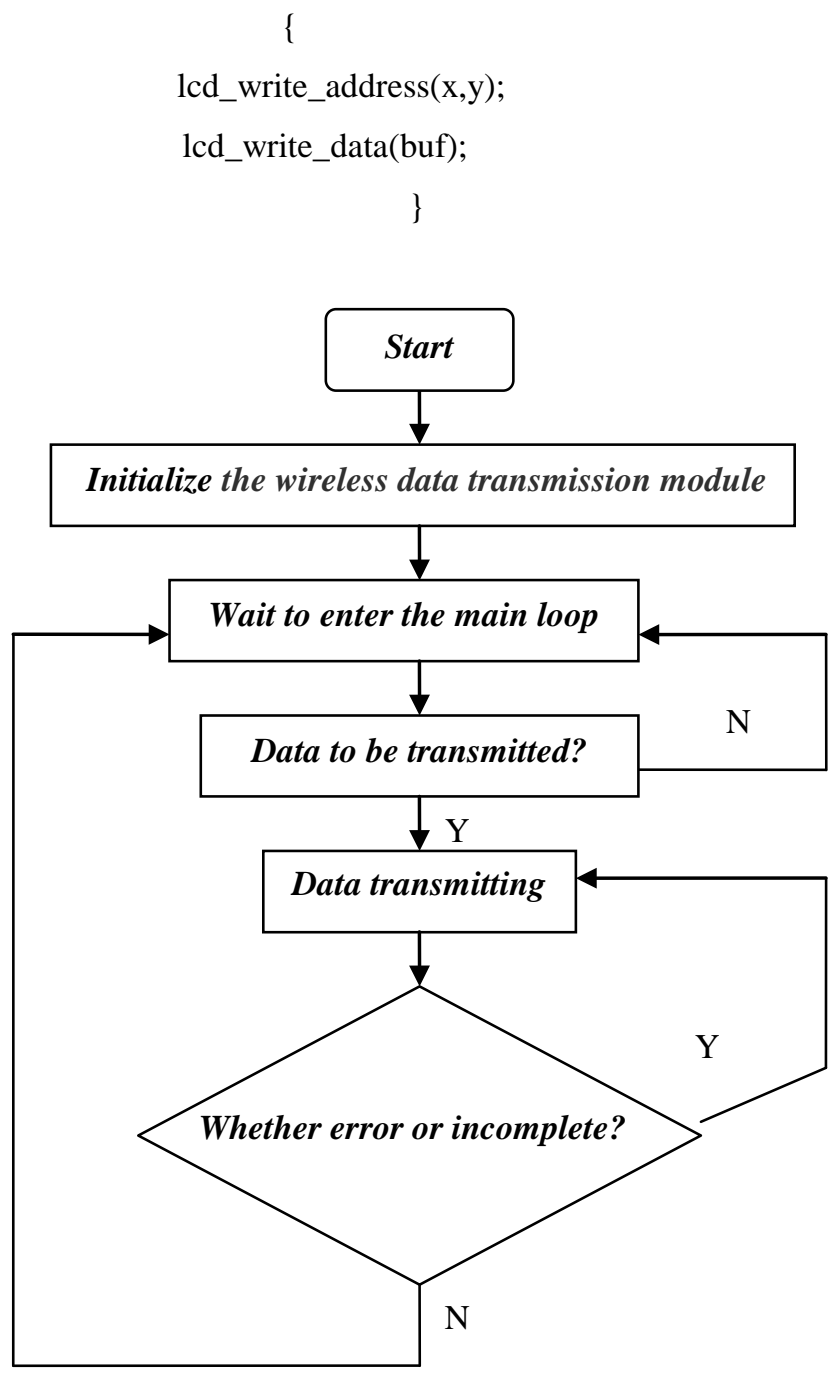

Fig. 2. Software flow chart of wireless data transmission

Part of the procedure is as follows:

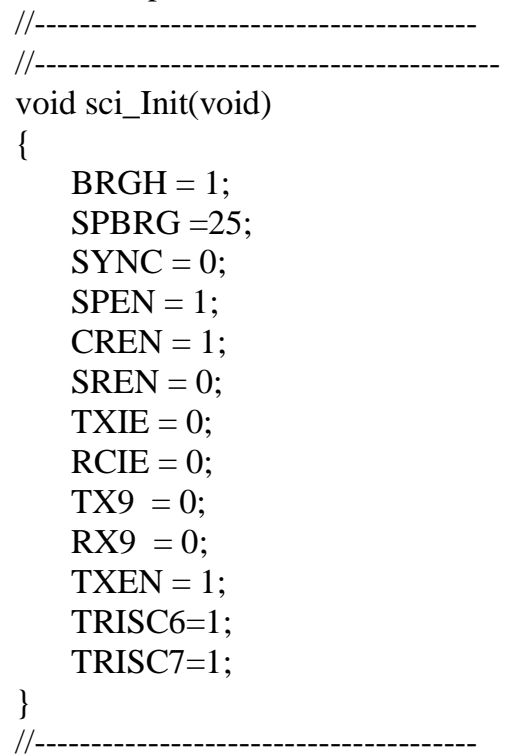

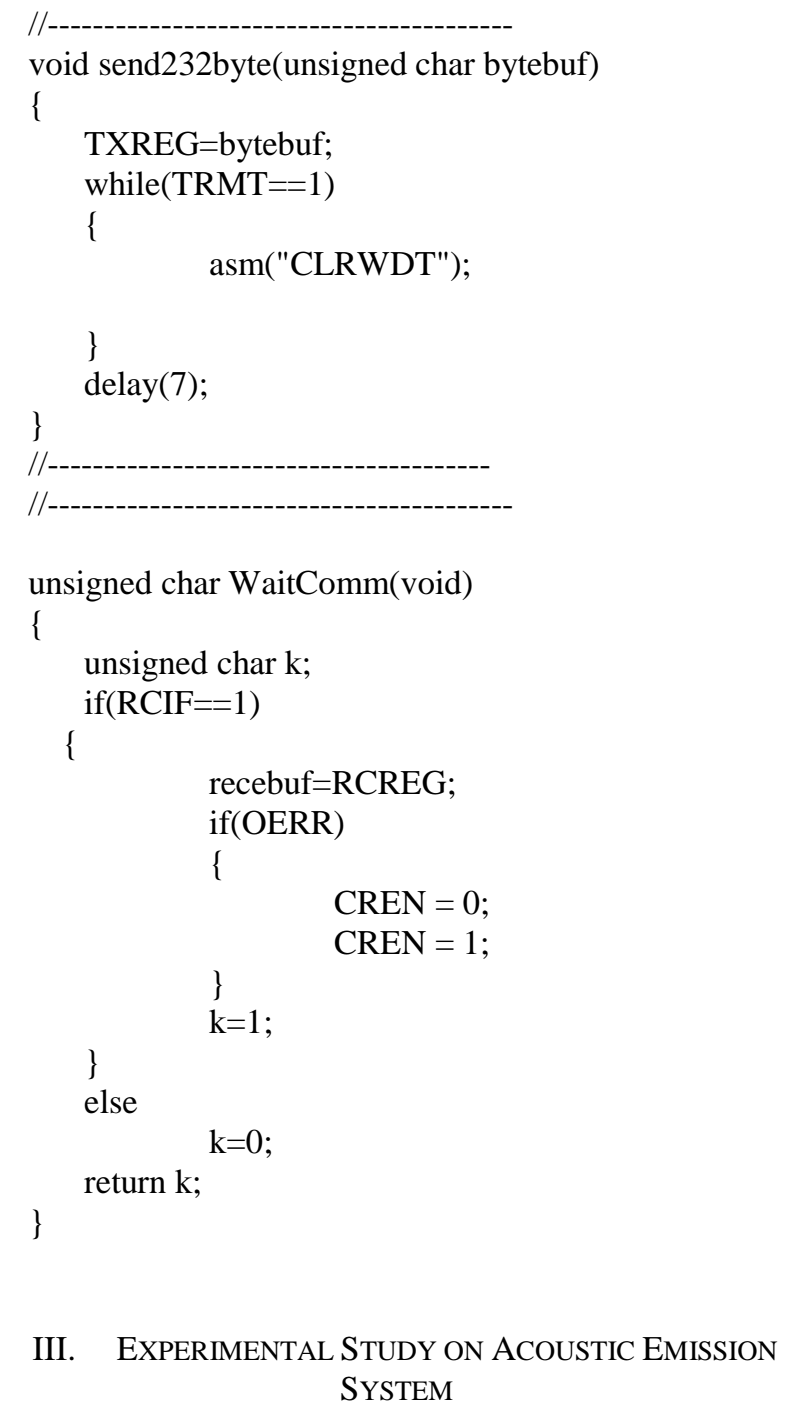

III. EXPERIMENTAL STUDY ON ACOUSTIC EMISSION SYSTEM

In order to test the $\mathrm{AD}$ acquisition and signal processing capability, the proteus software simulation is carried out in order to test the selected PIC microcontroller before the hardware test. And the $\mathrm{AD}$ transformation test was done by using ANO port of PIC Microcontroller to gather the divided voltage pressure of the glide rheostat. Because of the PIC has a built-in 10-bit high-accuracy AD converter, the results should between $0-1024$. The testing results have met the requirement, and drive 1602 was tested simultaneously. The data received by host computer was displayed and organized by using the serial assistant, the display as shown in Fig. 3 


$\begin{array}{ll}\text { Temp:23.4 } & \mathrm{AD}: 0565 \\ \text { Temp:23.4 } & \mathrm{AD}: 0564 \\ \text { Temp:23.4 } & \mathrm{AD}: 0565 \\ \text { Temp:23.4 } & \mathrm{AD}: 0564 \\ \text { Temp:23.4 } & \mathrm{AD}: 0564 \\ \text { Temp:23.4 } & \mathrm{AD}: 0565 \\ \text { Temp:23.4 } & \mathrm{AD}: 0564 \\ \text { Temp }: 23.4 & \mathrm{AD}: 0564 \\ \text { Temp:23.4 } & \mathrm{AD}: 0564 \\ \text { Temp:23.4 } & \mathrm{AD}: 0564 \\ \text { Temp:23.5 } & \mathrm{AD}: 0564 \\ \text { Temp:23.4 } & \mathrm{AD}: 0564 \\ & \\ \text { Temp:23.4 } & \mathrm{AD}: 0564 \\ \text { Temp:23.5 } & \mathrm{AD}: 0565 \\ \text { Temp:23.8 } & \mathrm{AD}: 0564 \\ \text { Temp:23.4 } & \mathrm{AD}: 0564\end{array}$

Fig. 3. Data display chart of wireless transmitting host computer

\section{CONCLUSION}

The application of safety monitoring system of rock mass acoustic emission into actual construction work has caused many problems. By analyzing the classical problems, a low cost, high performance safety monitoring system of rock mass acoustic emission which is able to complete wireless transmission has been established through adjustment of the present safety monitoring system. The experimental study of rock mass acoustic emission demonstrated that the improved system is suitable for the safety monitoring of rock mass.

\section{ACKNOWLEDGEMENTS}

This work was financially supported by "Twelfth Five Year" scientific and technological research project of The Education Department of Jilin Province ([2015] 281)

\section{REFERENCES}

[1] Shen Gongtian, Dai Guang, Liu Shifeng. Acoustic Emission Testing Progress in China: Celebration for The 25th Anniversary of Chinese Society for NDT, NDT, 2003(6):302 306

[2] Yuan Zhenming. The Development of Digital Acoustic Emission Instrument. Beijing: NDT, 1999(2):1 5

[3] Yin Xiangang, Li Shulin, Tang Haiyan. Study on Strength Fractal Features of Acoustic Emission in Process of Rock Failure. Liaoning: Chinese Journal of Rock Mechanics and Engineering, 2005 (19): 3512 3156

[4] Dj.M. Maric, P.F. Meier and S.K. Estreicher: Mater. Sci. Forum Vol. 8387 (1992), p. 119

[5] M.A. Green: High Efficiency Silicon Solar Cells (Trans Tech Publications, Switzerland 1987).

[6] Y. Mishing, in: Diffusion Processes in Advanced Technological Materials, edtied by D. Gupta Noyes Publications/William Andrew Publising, Norwich, NY (2004), in press. 